\title{
GREEN CHEMISTRY - A NOVEL APPROACH TOWARDS SUSTAINABILITY
}

\author{
PARTHA MUKHERJEE ${ }^{a, b^{*}}$ \\ ${ }^{a}$ Centre of Studies in Surface Science and Technology, School of Chemistry, Sambalpur University, Jyoti Vihar, Burla - 768019, INDIA. \\ ${ }^{b}$ HIL (India) Limited, A-4 Industrial Growth Centre, Mansa Road, Bathinda-151001, INDIA.
}

\begin{abstract}
A study on the emergence and twelve principles of Green chemistry has been thoroughly discussed. Syntheses of polymers and nanoparticles with the aid of greener method have been elucidated. Phase transfer catalysis is found to play Key role in the synthesis of various multistep processes to one pot cascade reaction. Ionic liquids have emerged out as alternative green solvent in synthetic chemistry replacing traditional organic ones due to environmental and health concerns. Non ionic surfactants notably due to their characteristic temperature induced clouding phenomena and subsequent phase separation above cloud point have been found potential application in the field of preconcentration and extraction of various metal ions, organic and inorganic industrial pollutants and pesticides.
\end{abstract}

Keywords: Green Chemistry, phase transfer catalysis, ionic liquids, nano synthesis, cloud point technology.

\section{INTRODUCTION}

Green chemistry, a concept developed in early '90s by the US environmental protection agency (EPA), has become a magic wand in the present chemical scenario. Common chemical practices, such as setting up of chemical industries in the field of petroleum, essential laboratory chemical agents, metal and solvent extraction processes, drug industries, fertilizer factories, and many more have become a blessing for the humanity. However, it is an irony that these industries have completely changed the natural atmosphere on the earth by inviting unnecessary pollution of soil, water, air and the whole of the basic necessities through solid waste production, gaseous emission and fluid spilling. It is high time to control the pollution in every avenue of life by adopting alternative pathways in production of chemical substances and their uses. The more intellectual approach to solve this problem is to follow the oldest proverb "prevention is better than cure" by developing methods and innovating technologies, which do not create any harm to the environment directly or indirectly. The pollution caused by synthetic chemicals has resulted in an increased demand for environmentally friendly chemical processes. Such an approach to prevent pollution for saving humanity from dangerous chemical hazards, which began intensively in economically developed countries in the 1990s, acquired the somewhat unusual name of green chemistry (1).

Green chemistry leads to the search for new processes and technologies which from the very beginning are aimed to prevent or cut short environmental pollution by reducing the volumes of chemical wastes and their toxicity, using harmless materials or materials safer than those currently used, as the starting materials. This science is currently in a stage of explosive growth and development. The development of "Green Chemistry" has emerged as a new avatar to solve this problem in order to secure the environment for the future $(1,2)$. Heterogeneous catalysis, bio-catalysis, solvent-less synthesis, use of microwaves and ultrasound, etc. are part of green chemistry. However, many argue that green chemistry is not a new concept as it is made to believe, rather, it is the proverbial 'old wine in a new bottle (3).

The origin of green chemistry can be traced back to the Solvay process invented in 1811 for the manufacture of soda ash $\left(\mathrm{NaCO}_{3}\right)$ from common salt and $\mathrm{CaCO}_{3}$. By 1873 , the Solvay process came to the centre stage replacing the polluting Le- Blanc process, based on $\mathrm{CaCO}_{3}$ and $\mathrm{Na}_{2} \mathrm{SO}_{4}$, which was practiced since 1787, wherein $\mathrm{Na}_{2} \mathrm{SO}_{4}$ was produced from $\mathrm{NaCl}$ and $\mathrm{H}_{2} \mathrm{SO}_{4}$. The irritating problems of disposal of $\mathrm{CaSO}_{4}$ were never suitably solved, and enormous quantities of left-over calcium sulphate are still indisposed in Europe.

Various organizations have defined green chemistry in varieties of ways. The International union of pure and applied chemistry (IUPAC) defines green chemistry as "the invention, design, and application of chemical products and processes to reduce or to eliminate the use and generation of hazardous substances"; the EPA gives the definition, "the use of chemistry for source reduction"; and the Organization for Economic Cooperation and Development
(OECD) gives the definition, "sustainable chemistry". These definitions seem to be different from the way they are expressed, but they lead to the same meaning and goal, that is, the objectives of green chemistry are to design, manufacture and use of efficient, effective, safe and more environmentally benign chemical products and process leading to the control of environmental pollution.

\section{PRINCIPLES OF GREEN CHEMISTRY}

The basic principles of green chemistry have been suggested for the first time by Paul Anastas and John Warner in 1998. According to them green chemistry consists of twelve principles which later on get a wider acceptance to give a brand new concept of green chemistry $(1,4-12)$.

1. Prevention. It is better to prevent waste than to treat or clean up waste after it has been created.

2. Atom Economy. Synthetic methods should be designed to maximize the incorporation of all materials used in the process into the final product.

3. Less Hazardous Chemical Syntheses. Wherever practicable, synthetic methods should be designed to use and generate substances that possess little or no toxicity to human health and the environment.

4. Designing Safer Chemicals. Chemical products should be designed to affect their desired function while minimizing their toxicity.

5. Safer Solvents and Auxiliaries. The use of auxiliary substances (e.g., solvents, separation agents, etc.) should be made unnecessary wherever possible and innocuous when used.

6. Design for Energy Efficiency. Energy requirements of chemical processes should be recognized for their environmental and economic impacts and should be minimized. If possible, synthetic methods should be conducted at ambient temperature and pressure.

7. Use of Renewable Resources. Use of raw materials and feedstocks that are renewable rather than depleting. Renewable feedstocks are often made from agricultural products or are wastes of other processes; depleting feedstocks are made from fossil fuels (petroleum, natural gas or coal) or are mined.

8. Reduce Derivatives. Unnecessary derivatization (use of blocking groups, protection/ deprotection, temporary modification of physical/chemical processes) should be minimized or avoided if possible, because such steps require additional reagents and can generate waste.

9. Use catalysts, not stoichiometric reagents. Minimize wastes by using catalytic reactions. Catalysts are used in small amounts and can carry out a single reaction many times. They are preferable to stoichiometric reagents, which are used in excess and work only once.

10. Design for Degradation. Chemical products should be designed so that at the end of their function they break down into innocuous degradation products and do not persist in the environment.

11. Real-time analysis for Pollution Prevention. Analytical methodologies need to be further developed to allow for real-time, in-process monitoring and control prior to the formation of hazardous substances.

12. Inherently Safer Chemistry for Accident Prevention. Substances and the form of a substance used in a chemical process should be chosen to minimize the potential for chemical accidents, including releases, explosions, and fires. 


\section{GREEN CHEMISTRY APPLICATIONS IN SYNTHESIS}

\subsection{Synthesis of polymer}

\section{a. Synthesis of polycaprolactone}

Poly ( $\varepsilon$-caprolactone) (PCL) is an important biocompatible and biodegradable polymer, which could be used as a synthetic material in multiple biomedical and environmental applications such as prostheses and controlled drug release matrix for active substances. This polymer is obtained by ring-opening polymerization of $\varepsilon$-caprolactone (Figure 1).

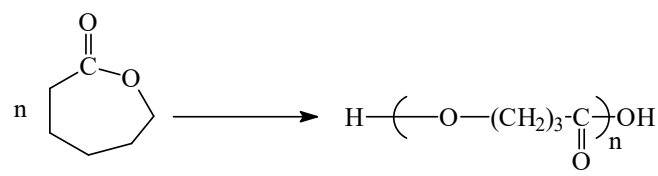

\section{Figure 1}

A wide variety of catalysts could be used for this synthesis (13-16) and lanthanide-based catalytic systems proved to be highly active in ring-opening polymerization (17-21). Stuerga et al. (22) has reported a new synthetic pathway of PCL using microwave irradiation without any solvent, using nontoxic, biologically acceptable lanthanide halides as initiators instead of using expensive lanthanide alkoxides.

\section{b. Synthesis of polyurethane}

Polyurethane is widely used in the manufacture of plastic foams, cushions, rubber goods, synthetic leathers, adhesives, paints and fibers. Enzyme-catalyzed polymerization and degradation can play an important role in both the synthesis and chemical recycling of green and sustainable polyurethane. Novel synthetic routes to polyurethane production without using diisocyanate have recently been developed. Kihara et al. (23) synthesized optically active polyurethane bearing hydroxyl and carboxyl groups by the polyaddition of L-lysine hydrochloride and a bifunctional five-membered cyclic carbonate (Figure 2).

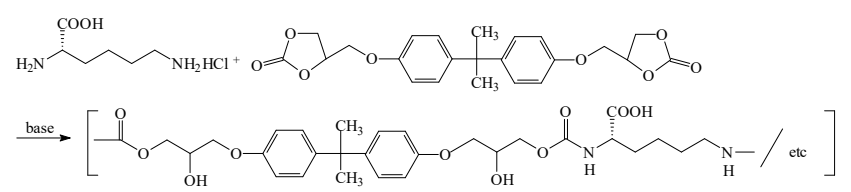

\section{Figure 2}

Tomita et al. (24) synthesized a series of polyhydroxyurethane by the polyaddition of the bifunctional five-membered cyclic carbonate and diamine (Figure 3).

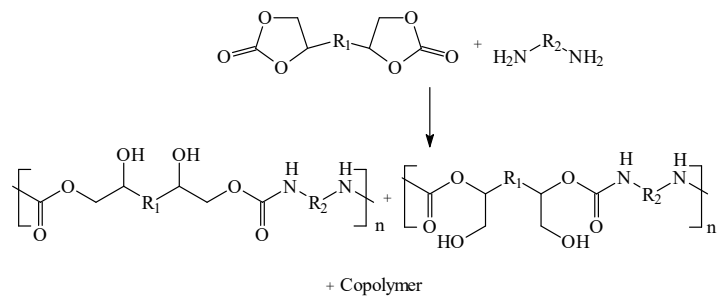

Figure 3

Rokicki and Piotrowska et al. (25) synthesized polyurethanes from commercially available ethylene carbonate, diamines, and diols (Figure 4).

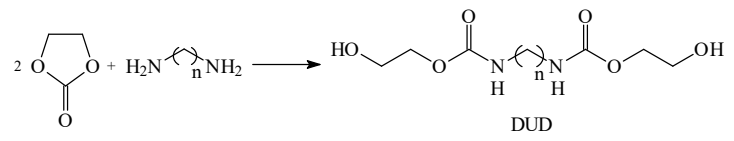

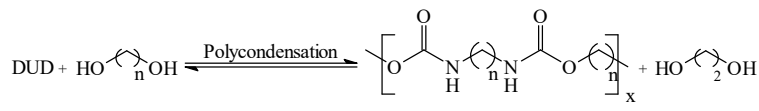

Figure 4
Neffgen et al. $(26,27)$ and Kusan et al. $(28)$ introduced an alternative route to synthesize poly (trimethylene urethane) and poly(tetramethylene urethane) by cationic ring opening polymerization of trimethylene urethane and tetramethylene urethane in a melt at $100^{\circ} \mathrm{C}$ (Figure 5).

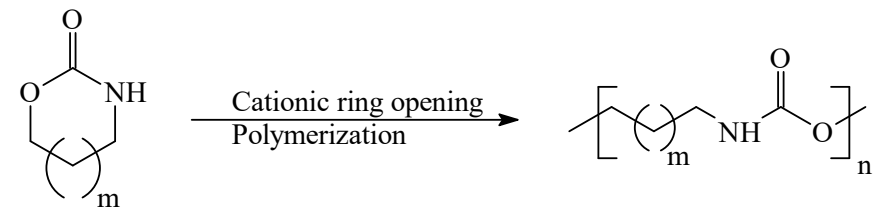

\section{Figure 5}

Schmitz et al. (29) described the copolymerization of 2, 2-dimethyltrimethylene carbonate with tetramethylene urea as a new route to polyurethane containing the urethane bond (Figure 6).

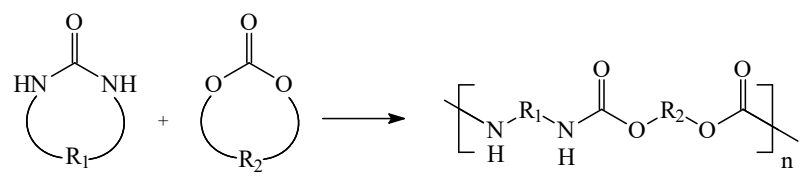

\section{Figure 6}

Ihata et al. (30) reported the novel synthesis of thermoresponsive polyurethane from 2-methylaziridine and supercritical carbon dioxide to give a polymer with a high content of urethane units and unique temperature-sensitive phase transitions in water (Figure 7).

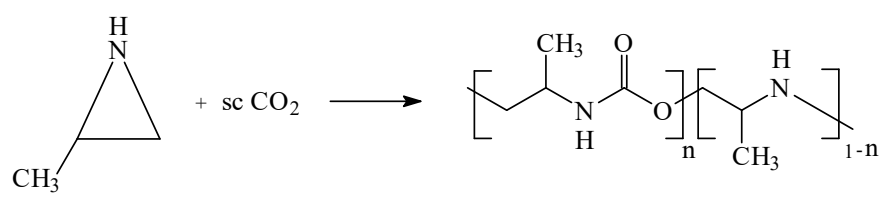

\section{Figure 7}

\subsection{Synthesis of Resoacetophenone (2,4-Dihydroxyacetophenone)}

2,4-Dihydroxyacetophenone, also known as resoacetophenone, finds wide applications as an intermediate in the manufacture of pharmaceuticals, perfumes(31), fine chemicals (32), cosmetics (33) and leukotriene antagonists (34). Resoacetophenone is used in spectrophotometric determination of iron (35) and its application in sunscreen composition has also been reported (36). It is employed as intermediate for the preparation of allergy therapeutic agents (37), UV-screening cosmetics (38), food preservative (39) and as a honey bee repellent (40). It is generally prepared by the acylation of resorcinol with acetic acid in the presence of a molar excess of zinc chloride, which leads to waste disposal problems. The most frequently used acylating agents such as acetic anhydride and acetyl chloride have several disadvantages and need to be replaced by cheap and benign agents.

Yadav et al. (41) synthesized 2,4- dihydroxyacetophenone from resorcinol and acetic acid by employing various solid acid catalysts (Figure 8). Amberlyst-36 was found to be the most suitable catalyst for this acylation reaction.
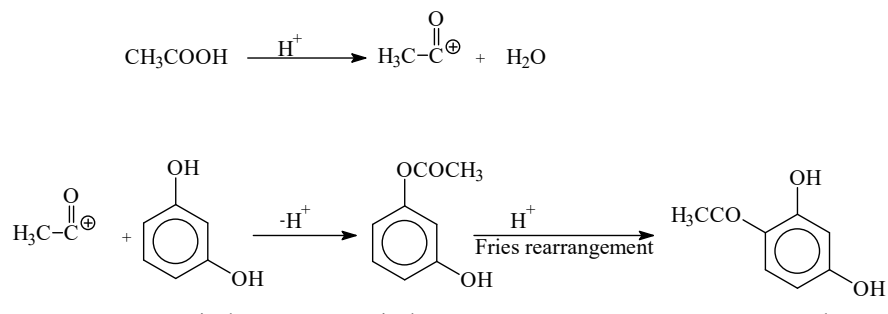

Resorcinol

Figure 8 


\subsection{Green chemistry in nano synthesis}

Nanomaterials have gained momentum in the field of science and technology. Various chemical and mechanical methods are being adopted for the preparation of nanomaterials. Mechanical stimulation helps in enhancing chemical reaction overcoming activation energy barrier easily (42). Mechanochemical synthesis has emerged as an alternative route and waste free ecologically safe method for the synthesis of composite formation (43). Mechanochemical processes allow the synthesis of materials with controlled homogeneity and nanocrystaline form as well as mixing the components at atomic level. Wieczorek-Ciurowa et al. (44) reported the successful spreading of vanadium oxide on chromia surface using high energy ball milling. This enrichment of surface catalyst with vanadium increases the catalytic activity and can be used for the oxidative dehydrogenation of propane (45). Wieczorek-Ciurowa et al. $(46,47)$ reported the synthesis of $\mathrm{Cu}$ $\mathrm{Al} / \mathrm{Al}_{2} \mathrm{O}_{3}$ nanocomposite from two different systems of precursors, i.e. $\mathrm{CuO}-\mathrm{Al}$ and $\mathrm{Cu}_{2}(\mathrm{OH})_{2} \mathrm{CO}_{3}-\mathrm{Al}$, using a high-energy ball mill. $\mathrm{Cr}_{1.23} \mathrm{Al}_{0.77} \mathrm{O}_{3}$, a pigment based on chromia, has been visualized as green pigment.

The synthesis of this green pigment was reported by mechanochemical method at room temperature using $\mathrm{Cr}_{2} \mathrm{O}_{3}$ as a precursor. This method was based on highenergy ball milling created the possibility of obtaining the nanocrystalline form of pigment (48-51).

Zeng et al. (52) have reported a unique "green" method for the synthesis of copper nanoparticles with average diameter less than $5 \mathrm{~nm}$ in aqueous solution with natural vitamin C i.e., ascorbic acid as reductant and antioxidant (Figure 9) in the presence of polyvinylpyrrolidone (PVP) as a stabilizer.

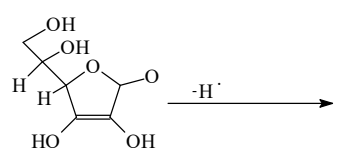

L-Ascorbic acid

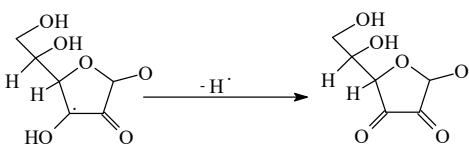

Dehydroascorbicacic
Figure 9. Antioxidation mechanism of ascorbic acid

Gonzal et al. (53) reported successful synthesis and characterization of $\mathrm{H}_{2} \mathrm{~V}_{3} \mathrm{O}_{8}$ nano belts about $100 \mathrm{~nm}$ wide and several micrometers long from commercial $\mathrm{V}_{2} \mathrm{O}_{5}$ powder using fast and eco friendly microwave-hydrothermal method. An environmental friendly ex-situ synthetic route of silver nanocomposite films was depicted using colloidal silver dispersion and potato starch/glycerol matrix. Size and distribution of nanoparticles were optimized with the variation of glucose content in polymer matrix and reaction time (54). Synthesis of extracellular silver nanoparticles with the application of facile, rapid and inexpensive aqueous leaf extract technology was described and characterized by Fourier transformed infrared spectroscopy (FT-IR), X-ray diffraction (XRD), scanning electron microscopy and transmission electron microscopy (TEM) (55). Synthesized silver nanoparticles were reported to manifest antibacterial properties.

\section{GREEN CHEMISTRY IN CATALYSIS}

Aromatic nitro compounds found their importance as intermediate in agrochemicals, pharmaceuticals, dyestuffs, urethanes and other industrially important products (56-58). Numerous methods for the reduction of aromatic nitro compounds have been developed in recent times using catalytic hydrogenation processes (59-83). However, these methods are associated with (i) serious environmental pollution from residue, (ii) significant limitations based on safety and handling considerations, (iii) strong acidic or alkaline media, and (iv) reaction conditions leading to destruction of many sensitive functional groups. Hence, recently more attention is being paid to "green chemistry".

Zheng et al. (84) have reported the use of $\mathrm{Ni} / \mathrm{SiO}_{2}$ catalyst as an efficient, mild and practical method for the reduction of aromatic nitro compounds. They successfully prepared and characterized the catalyst by XRD, FT-IR, TEM, and SEM and reported that the catalyst passivated with a gas mixture could be stored safely in air below $423 \mathrm{~K}$ and could be used without farther activation.

Phase transfer catalysis (PTC) has emerged as an important area of green chemistry. PTC reactions have been exploited for their selectivity engineering and environmental aspects $(85,86)$. Fenvalerate, a widely used synthetic pyrethroid insecticide, was synthesized by a multistep process. In order to remove the complexities in fenvalerate synthesis, Yadav et al. (87) reported a unique one pot cascade engineered phase transfer catalysis method (CEPTC) using tetrabutyl ammonium bromide (TBAB) to minimize the generated waste of few steps of fenvalerate synthesis. CEPTC method has widely been exploited for the conversion of benzyl chloride into various industrially important products such as benzyl alcohol (through hydrolysis), dibenzyl ether (through hydrolysis), phenylacetonitrile (through nitrile substitution), benzyl esters (through esterification), phenyl acetic acid (through the hydrolysis of phenylacetonitrile) (Figure10). The cascade reaction system itself is novel where from one starting material a variety of products are obtained by changing the parameters.

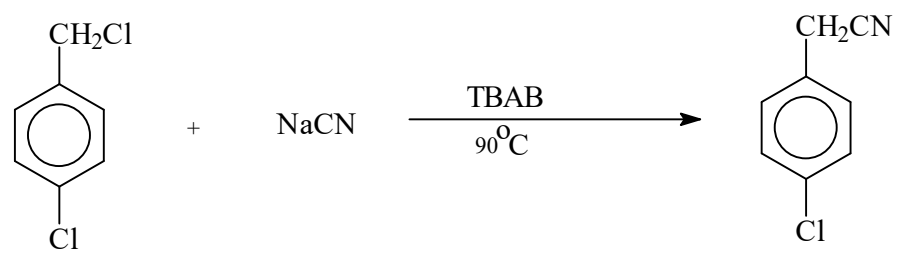

Step-I

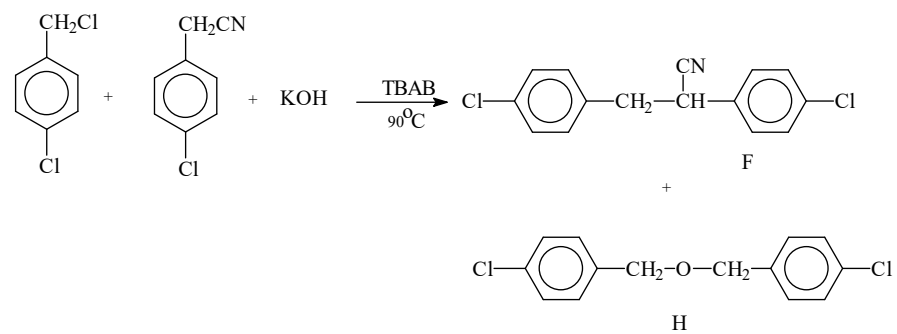

Major Product

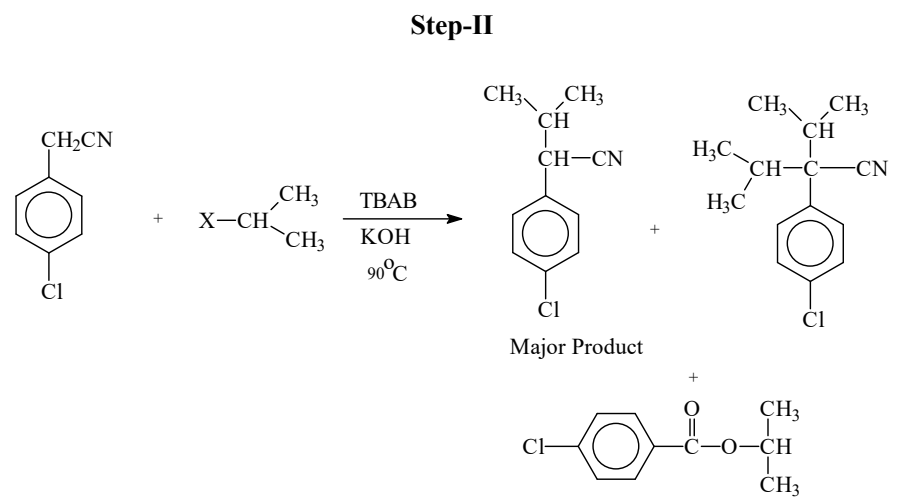

Step-III

\section{Figure 10}

Marui et al. (88) oxidized benzhydrols in a unique method under an atmosphere of $\mathrm{O}_{2}$ using water as the green solvent replacing organic solvents catalyzed by oxovanadium-4,4'-t-Bubpy (4,4'-di-tert-butyl-2,2'-bipyridyl) complex.

\section{SOLVENTS IN GREEN CHEMISTRY}

The largest amount of auxiliary waste is associated with the use of solvent in any chemical reaction. In a classical chemical process, solvents are used extensively for dissolving reactants, extracting and washing products, separating mixtures, cleaning reaction apparatus, and dispersing products for practical applications. There has been marvelous advancement in chemistry with the invention of exotic organic solvents as well as the legacy of such solvents leading to various environmental and health concerns. At such a juncture, green chemistry has come out as savior through the evolution of a variety of cleaner solvents replacing the exotic solvents (89). Among the most widely explored greener solvents are ionic liquids (90), supercritical $\mathrm{CO}_{2}(91)$ and water (92). These solvents complement each other nicely both in properties and applications. 
Importantly, the study of green solvents goes far beyond just solvent replacement. The use of green solvents has led science to uncharted territories. For example, the study of ionic liquids made large-scale supported synthesis possible for the first time (93) and the utilization of supercritical $\mathrm{CO}_{2}$ has led to breakthroughs in microelectronics and nanotechnologies (94). Although water is the most abundant natural and non-toxic solvent on earth, it has been traditionally treated as a nuisance in most chemical productions. However, Breslow's report on the acceleration of Diels-Alder reactions in aqueous media (95) led to reexamine this solvent for chemical applications. The commercialization of aqueous-based hydroformylation and hydrogenation processes allow product separation and catalyst recycling readily (96). The development of aqueous organometallic reactions simplifies protection-deprotection of functional groups and allows the direct use of biomass-based feedstocks for synthetic purposes (97). The innovative “on-water" concept (98), water-tolerant Lewis acids (99) and aqueous organocatalyses (100) led to new understandings of fundamental chemical reactivities.

\subsection{Ionic liquids as green solvent}

The most of ionic liquids (ILs) are clear, colorless low melting viscous liquid possessing a unique array of physico-chemical properties such as high electrical conductivity, high thermal stability, low nucleophilicity and capability of providing weekly coordinating or noncoordinating environment, very good solvents properties for an extensive diversity of organic, inorganic, organometallic and polymeric compounds (101). These solvents can be readily removed and recycled (102-104) and these properties enable room temperature ionic liquids (RTIL) to give a wider acceptance as possible "green" solvents, which substitute classical volatile organic solvents in a variety of processes, including industrially essential chemical process $(105,106)$.

ILs have gained application in polycondensation reactions $(101,107-110)$. Mallakpoor et al. (111) have explored for the first time the tetrabutylammonium bromide (TBAB), a molten ionic liquid(MIL), to act as a novel and efficient green media for the synthesis of polyamides (PA) from the reaction of dicarboxylic acids with diisocyanates replacing toxic and volatile organic solvent $N$-methylpyrrolidone (NMP) with or without dibutyltin dilaurate (DBTDL) as a catalyst (Figure 11).

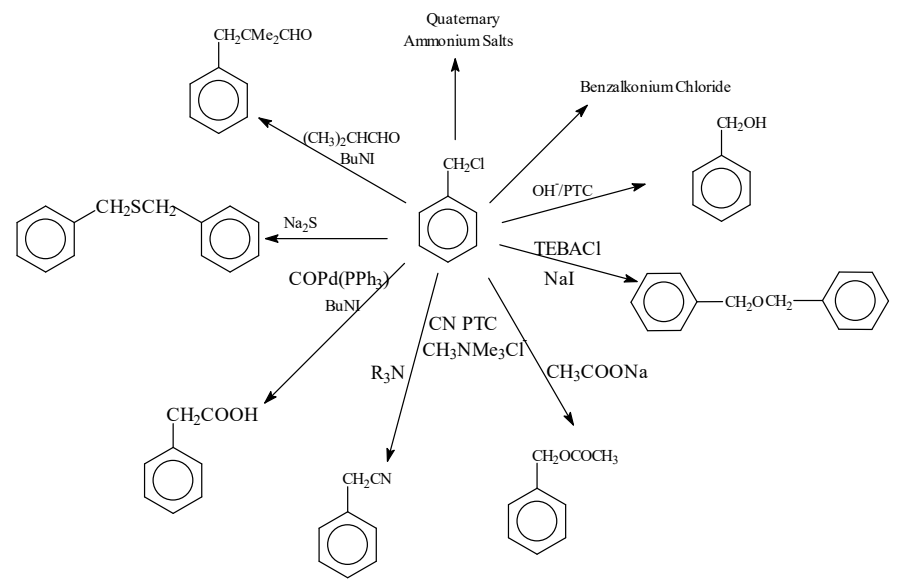

Figure 11. It was also observed that molten $\mathrm{TBAB}$ can act both as solvent and catalyst.

Several new functionalized imidazolium-based ionic liquids were prepared in a green ultrasound assisted route and characterized by spectroscopic studies (112).

\section{SURFACTANTS IN GREEN CHEMISTRY}

Green chemistry deals with the utilization of renewable resources, combined with recycling in order to develop chemical reactions combined with enzymatic action (chemoenzymatic) at moderate temperatures, pressures, and $\mathrm{pH}$ conditions (113-116). Sugar-based surfactants developed from renewable resources such as sorbitan esters, sucrose esters, alkyl polyglycosides, and fatty acid glucamides (117), were found to satisfy the demands of performance, consumer safety and environmental compatibility. Due to their characteristic surface activity and/or tendency to form molecular self-assembly, surfactants can control and modify both physical and chemical properties of the phase boundary between different phases such as liquid (water)-liquid (oil), which are encountered in almost all chemical reactions. Most of the chemical reactions occur in organic media to maintain the homogeneity of reaction medium and accelerate the reaction rate. Green chemistry promotes the use non-organic solvents or the innovation of such system which does not require organic solvent. Surfactants have emerged to control reactions based on different phases such as liquid (water)-liquid (oil) in a nonorganic solvent reaction system due to their appropriate hydrophobiclipophobic balance (HLB). Thus surfactant system leads to achieve several objectives including a nonorganic water solvent system, clean reaction conditions, high yields of halide-free products, waste reduction, simplicity of operation (product separation), cost effectiveness (catalyst recycling), etc. (118).

Surfactants play their crucial role in phase transfer catalysis. Alkyl ammonium salts, specially tetrabutylammonium bromide, is widely used as phase transfer catalyst (PTC) in many chemical reactions. Sato et al. (119) reported the oxidation of primary and secondary alcohols under entirely halide-free conditions (organic/aqueous biphasic conditions) using 3-30\% hydrogen peroxide in the presence of a tungsten catalyst and lipophilic quaternary ammonium hydrogen sulfate, as PTC (Figure 12).

The quaternary ammonium hydrogen sulphate plays a crucial role for higher reactivity due to its acidity. Epoxidation of olefins using the similar type of phase transfer catalyst have also been reported (120).

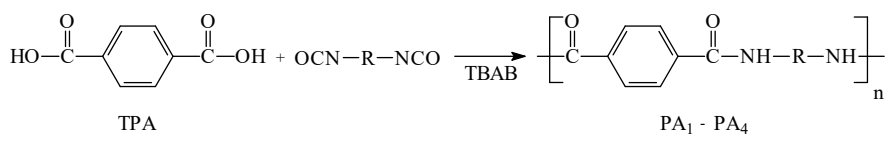

\section{Figure 12}

Preconcentration or extraction of metal ion using cloud point technology (CPT) has been widely studied since the last decade of twentieth century as it fulfills the criteria of green chemistry replacing the solvent extraction technique. Nonionic and zwitterionic surfactants in their aqueous solution above their critical micellar concentration or in microemulsion, when heated above certain temperature, become turbid leading to phase separation. CPT has got importance due to its potential application in removing industrial pollutants and hazardous chemicals. Feng et al. (121) extracted phenol and vanadium ion using cloud point technology in aqueous solution formed by the combination of $\mathrm{CO}_{2}$ and Triton X-100.

They also reported the synthesis gold nanoparticles in micellar solution of TX100 in presence of $\mathrm{CO}_{2}$. Farajzadeh et al. (122) extracted $\mathrm{Cu}(\mathrm{II}), \mathrm{Cr}(\mathrm{III}), \mathrm{Fe}(\mathrm{III})$, $\mathrm{Mn}(\mathrm{II}), \mathrm{Pb}(\mathrm{II}), \mathrm{Cd}(\mathrm{II})$ and $\mathrm{Zn}$ (II) from water samples using the TX-114 surfactant and 8-quinolinol ligand. Genc et al. reported (123) extraction and determination of Vanadium using 4-(2-thiazolylazo) resorcinol in TX-100. Mukherjee et al. (124-125) and S.K. Padhan et al. (126) utilized the clouding behavior of microemulsions of pseudoternary mixtures of Tween $80 /$ butanol/water and kerosene or hexane as oil for the preconcentration of some styryl pyridinium dyes and metal ions like $\mathrm{Ni}, \mathrm{Cu}$ and $\mathrm{Co}$. Triazine, a recognized herbicide, widely used in agro industry was preconcentrated utilizing cloud point extraction technology prior to determination by High-performance liquid chromatography in milk samples (127). Makukha et al (128) reported extraction of nimesulide, a nonsteroidal anti-inflammatory drug in biological samples using TX-100 and TX-114.

\section{CONCLUSION}

The rapid industrialization and urbanization in modern era only to achieve economic growth lead the Globe, creature of GOD to uncertain destiny as a consequence of pollution of soil, water and air, the three pillars of living kingdom. Various incurable diseases are the manifestation of consequences of environmental pollution. Green chemistry has emerged out as necessity at this juncture. To safeguard and sustenance of living kingdom, it is mandatory to restore ecological balance. This can only be achieved with the advent, use and production of green chemicals and carrying out chemical transformations through procedures laid down by practitioners of green chemistry. The earth and all the living creatures exist in it are to be saved from the ensuing disaster through such practices only. 


\section{REFERENCES}

1. P.T. Anastas, J.C. Warner, Green Chemistry: Theory and Practice; Oxford Sci. Publ.: Oxford, 1998.

2. (2) P.T. Anastas, T.C. Williamson, Green Chemistry: An Overview. In Green Chemistry:Designing Chemistry for the Environment, T.C., Eds.; ACS Symposium Series 626; American Chemical Society: Washington, DC, 1996, pp 1-17.

3. G.D. Yadav, Clean Techn. Environ. Policy, 8, 219-223, (2006).

4. P.T. Anastas, T.C. Williamson, Green Chemistry: Frontiers in Benign Chemical Syntheses and Processes; Oxford University Press: Oxford, 1998.

5. P.T. Anastas, L.G. Heine, T.C. Williamson, In Green Chemical Syntheses and Processes; ACS Symposium Series 767, American Chemical Society, 2000, pp.1-6.

6. P. Tundo, P.T. Anastas, Green Chemistry. Challenging Perspectives; Oxford University Press: Oxford, 2000

7. J. Clark, D. Macquarrie, Handbook of Green Chemistry and Technology, Blackwell Publishing: Oxford, 2002.

8. M. Lancaster, Green Chemistry. An Introductory Text; Royal Society of Chemistry: Cambridge, 2002.

9. P.T. Anastas, M.M. Kirchoff, Acc. Chem. Res. 35, 686-694, (2002).

10. M.A. Ryan, M. Tinnesand, Introduction to Green Chemistry. Instructional Activities for Introductory Chemistry; American Chemica Society, Washington, 2002.

11. M.C. Cann, M.E. Connelly, Real-World Cases in Green Chemistry; American Chemical Society, Washington, 2000.

12. A. Gałuszka, Z. Migaszewski, J. Namieśnik, TrAC, Trends in Analytical Chemistry 50, 78-84, (2013).

13. I. Barakat, P. Dubois, R. Jerome, Macromolecules 24, 6542-6545, (1991).

14. A. Duda, S. Penczek, Macromolecules 28, 5981-5992, (1995).

15. J. Okuda, P. Koenig, S. Ngo, I. Rushkin, Polym. Prep. 35, 524-525, (1994).

16. H.R. Kricheldorf, K. Hauser, Macromolecules 31, 614-620, (1998).

17. S. Agarwal, M. Karl, S. Anfang, K. Dehnicke, A. Greiner, Polym. Prepr. 39,361-362, (1998).

18. W.M. Stevels, M. Ankone, P. Dijkstra, J. Feijen, Macromolecules 29, 3332 3333, (1996).

19. D. Barbier-Baudry, A. Bouazza, C.H. Brachais, A. Dormond, M. Visseaux, Macromol. Rapid Commun. 21, 213-217, (2000).

20. W.J. Evans, H. Katsumata, Macromolecules 27, 2330-2332, (1994).

21. M. Visseaux, C.H. Brachais, C. Boisson, K. Tortosa, C R Acad. Sci. Paris, Serie IIc, Chimie 3, 631-638, (2000).

22. D. Barbier-Baudry, L. Brachais; A. C. R.. Gattin; A. Loupy, D. Stuerga,Environ. Chem. Lett.2003, 1, 19-23.

23. N. Kihara, Y. Kushida, T. Endo, J. Polym. Sci.,Part: A Polym. Chem. 34, 2173-2179, (1996).

24. H. Tomita, F. Sanda, T. Endo, J. Polym. Sci., Part: A Polym. Chem. 39, 851$859,(2001)$

25. G. Rokicki, A. Piotrowska, Polymer 43, 2927-2935, (2002)

26. S. Neffgen, H. Keul, H. Höcker, Macromolecules 30, 1289-1297, (1997)

27. S. Neffgen, H. Keul, H. Höcker, Macromol. Chem. Phys. 199, 197-206, (1998).

28. J. Kusan, H. Keul, H. Höcker, Macromolecules 34, 389-395, (2001).

29. F. Schmitz, H. Keul, H. Höcker, Polymer 39, 3179-3186, (1998).

30. O. Ihata, Y. Kayaki, T. Ikariya, Angew Chem. Int. Ed. 43, 717-719, (2004).

31. T. Kanechika, S. Osada, N. Ando, Jpn Kokai Tokkyo Koho, JP 02011536, 1990.

32. K. Tanaka, K. Goto, Jpn Kokai Tokkyo Koho, JP 61176548, 1986.

33. T. Satoh, H. Matsumoto, T. Miki, PCT Int. Appl., WO 9205137, 1992.

34. W.S. Marshall, S.K. Sigmund, Whitesitt, C.A. US Patent 4,777, 298, 1988

35. G.S. Chowdary, N. Appalaraju, Current Science 44, 343-344, (1975).

36. R. Bognar, M. Simon, L. Szodoray, M. Rakosi, I; Horkay, J. Balint, I. Kovacs, Hung Teljes 1728; CA 75:40439, 1971.

37. T. Fukumoto, J. Sato, T. Mori, T. Oonishi, Jpn Kokai Tokkyo Koho, JP 07291889,1995

38. T. Fukumoto, K. Ujita, T. Mori, K. Nakao, H. Tamai, Jpn Kokai Tokkyo Koho, JP 08225484, 1996

39. A. Nishina, Y. Sakurai, Jpn Kokai Tokkyo Koho, JP 06217747, 1994.

40. M. Gupta, Comp. Physiol. Ecol. 13, 64-68, (1988).

41. G.D. Yadav, A.V. Joshi, Clean Techn. Environ. Policy 4, 157-164, (2002).

42. B. Murty, S. Ranganathan, Int. Mater. Rev. 43, 101-141, (1998).

43. T. F. Grigor'eva, A. P. Barinova, N. Z. Lyakhov, J. Nanopart. Res. 5, 439453, (2003).

44. A. Gomu-czak, K. Wieczorek-Ciurowa, K. Gamrat, V. A. Zazhigalov on Ogólnopolskie Kolokwium Katalityczne, Kraków 15-18 marca 2006, Materia_y (Ed.-. Mokrzycki, IKiFP PAN Kraków Poland) (ISBN 83-6051400-3).
45. K. Wieczorek-Ciurowa, A. Gomu_czak, J. Rakoczy, K. Gamrat, J. Stoch, Z. Saw-ovicz, Pol. Jour. Applied Chem. 49, 253-262, (2005).

46. K. Wieczorek-Ciurowa, K. Gamrat, K. Fela, Solid State Ionics 164, 193-198, (2003).

47. K. Wieczorek-Ciurowa, K. Gamrat, Z. J. Saw-owicz, Therm. Anal. Calorim. 80, 619-623, (2005).

48. E. Ozel, S. Turan, J. Eur. Ceram. Soc. 23, 2097-2104, (2003).

49. S. M. Naga, I. S.F. Ahmed, D. M. Ibrahim, Ceram. Int. 21, 51-57, (1995).

50. P. Sulcová, M. Trojan, Dyes and Pigments 4, 83-86, (1998).

51. E. R. Munoz, N. Masó, B. Julián, F. Marquez, H. Beltran, P. Escribano, E. Cordoncillo, J. Eur. Ceram. Soc. 24, 2087-2094, (2004).

52. C. Wu, B. P. Mosher, T. Zeng, J. Nanoparticle Res. 8, 965-969, (2006).

53. J. Prado-Gonjal, B. Molero-Sánchez, D. Ávila-Brande, E. Morán, J. Carlos Pérez- Flores, A. Kuhn, F. García-Alvarado, J. Power Sourrces 232, 173 180, (2013).

54. P. Cheviron, F. Gouanvé, E. Espuche, Carbohydrate Polymers 108, 291298, (2014).

55. A. K. Deenadayalan, V. Palanichamy, S.M. Roopan, Spectrochim. Acta, Part A 127, 168-171, (2014).

56. G. Booth on Ullmanns encyclopedia of industrial chemistry; Wiley-VCH: Verlag, Weinheim, 2002.

57. a) F. Figueras, B. Coq, J. Mol. Catal. A: Chem. 2001, 173, $117-$ b) Figueras, F.; Coq, B. J. Mol. Catal. A: Chem. 2001, 173, 223-230.

58. Mitchell, S.C.; Waring, R.H. Ullmanns encyclopedia of industrial chemistry; Wiley-VCH: Verlag, Weinheim, 2000.

59. M.L. Kantam, T. Bandyopadhyay, A. Rahman, N.M. Reddy, B.M. Choudary, J. Mol. Catal. A: Chem. 133, 293-295, (1998).

60. S. Xu, X. Xi, J. Shi, S. Cao, J. Mol. Catal. A: Chem. 160, 287-292, (2000).

61. Chen, Y.; Qiu, J.; Wang, X.; Xiu, J. J. Catal. 2006, 242, 227-230.

62. Y. Du, H. Chen, R. Chen, N. Xu, Appl. Catal., A: Gen, 277, 259-264, (2004).

63. T. Joseph, K. Vijay Kumar, A.V. Ramaswamy, S.B. Halligudi, Catal. Commun. 8, 629-634, (2007).

64. a) F. Cardenas-Lizana, S. Gomez-Quero, M.A. Keane, Catal. Commun. 9, 475-481, (2008).

b) F. Cardenas-Lizana, S. Gomez-Quero, M.A. Keane, Appl. Catal., A: Gen 334 199-203, (2008)

65. T.T. Bovkun, M. Grayevsky, Y. Sasson, J. Bluma, J. Mol. Catal. A: Chem. 270, 171-176, (2007).

66. J.H. Shen, Y.W. Chen, J. Mol. Catal. A: Chem. 273, 265-276, (2007).

67. B. Basu, S. Das, P. Das, A.K. Nanda, Tetrahedron Lett. 46, 8591-8593, (2005).

68. K.V. Murthy, P.M. Patterson, G. Jacobs, B.H. Davis, M.A. Keane, J. Catal. 223, 74-85, (2004).

69. X. Xi, Y. Liu, J. Shi, S. Cao, J. Mol. Catal. A: Chem. 192, 1-7, (2003).

70. Y.S. Keum, Q.X. Li, Chemosphere 4, 255-263, (2004).

71. A. Corma, P. Serna, Science 313, 332-334, (2006).

72. A. Corma, P. Concepcion, P. Serna, Angew Chem. Int. Ed. 46, 7266-7269, (2007).

73. R. Raja, V.B. Golovko, J.M. Thomas, A. Berenguer-Murcia, W. Zhou, S Xie, B.F.G. Johnson, Chem. Commun. 2026-2028, (2005).

74. D. He, H. Shi, Y. Wu, B.Q. Xu, Green Chem. 9, 849-851, (2007).

75. A. S. Kulkarni, R.V. Jayaram, Appl. Catal. A: Gen 252, 225-230, (2003).

76. A. S. Kulkarni, R.V. Jayaram, J. Mol. Catal. A: Chem. 223, 107-110, (2004).

77. S.K. Mohapatra, S.U. Sonavane, R.V. Jayaram, P. Selvam, Tetrahedron Lett. 43(47), 8527-8529, (2002)

78. S.K. Mohapatra, S.U. Sonavane, R.V. Jayaram, P. Selvam, Org. Lett. 4(24), 4297-4300, (2002).

79. M. Benz, R. Prins, Appl. Catal. A: Gen 183, 325-333, (1999).

80. K. Abiraj, G.R. Srinivasa, D.C. Gowda, Aust. J. Chem. 58(2), 149-151, (2005).

81. K. Abiraj, G.R. Srinivasa, D.C. Gowda, Synth. Commun. 35(2), 229-236, (2005).

82. T.M. Jyothi, R. Rajagopal, K. Sreekumar, M.B. Talawar, S. Sugunanb, B.S. Rao, J. Chem. Res. (S), 674-675, (1999).

83. M.V. Joshi, D. Mukesh, J. Catal. 168, 273-278, (1997).

84. Y. Zheng, K. Ma, H. Wang, X. Sun, J. Jiang, C. Wang, R. Li, J. Ma, Catal. Lett. 124, 268-276, (2008)

85. G.D. Yadav, Y.B. Jadhav, Langmuir 18(16), 5995-6002, (2002).

86. G.D. Yadav, Y.B. Jadhav, J. Mol. Catal. A: Chem. 184(1-2), 151-160, (2002).

87. G.D. Yadav, Y.B. Jadhav, Clean Techn. Environ. Policy 6, 32-42, (2003).

88. K. Marui, Y. Higashiura, S. Kodama, S. Hashidate, A. Nomoto, S. Yano, M. Ueshima Ogawa, A. Tetrahedron 70 (14), 2431-2438, (2014).

89. R.A. Sheldon, Green Chem. 7, 267-278, (2005). 
90. R.D. Rogers, G.A.Voth, Acc. Chem. Res., special issue on ionic liquids, ed. 40 (11), (2007).

91. a) J.M. DeSimone, W. Tumas on Green Chemistry Using Liquid and Supercritical Carbon Dioxide, ed.; Oxford University Press: New York, 2003.

b) P.G. Jessop, W. Leitner, on Chemical Synthesis Using Supercritical Fluids, ed.; VCH/Wiley: Weinheim, 1999.

96. B. Cornils, W.A. Herrmann on Aqueous-Phase Organometallic Catalysis, ed; Wiley-VCH: Weinheim, 2004.

97. C.J. Li, Tetrahedron 52, 5643-5668, (1996).

98. S. Narayan, J. Muldoon, M.G. Finn, V.V. Fokin, H.C. Kolb, K.B. Sharpless, Angew. Chem., Int. Ed. 44, 3275-3279, (2005).

99. S. Kobayashi, M. Sugiura, H. Kitagawa, W.W.L. Lam, Chem. Rev., 102, 2227-2302, (2002).

100.N. Mase, Y. Nakai, N. Ohara, H. Yoda, K. Takabe, F. Tanaka, C.F. Barbas, J. Am. Chem. Soc. 128, 734-735 (2006).

101.S. Mallakpour, Z. Rafiee, Eur. Polym. J. 43, 1510-1515, (2007).

102.N. Gupta, Sonu, G.L. Kad, J. Singh, Catal. Commun. 8, 1323-1328, (2007).

103.A. Kamal, G. Chouhan, Adv. Synth. Catal. 346, 579-582, (2004).

104.L. Lopez, G. Silvero, M.J. Arevalo, R. Babiano, G.C. Palaciosa, J.L. Bravo, Tetrahedron 63, 2901-2906, (2007).

105.H.M. Meshram, P.N. Reddy, P. Vishnu, K. Sadashiv, J.S. Yadav, Tetrahedron Lett. 47, 991-995, (2006).

106.B.C. Ranu, Jana, R. Eur. J. Org. Chem. 3767-3770, (2006).

107.Y.S. Vygodskii, E.I. Lozinskaya, A.S. Shaplov, Macromol. Rapid Commun. 23, 676-680, (2002).

108.S. Mallakpour, Z. Rafiee, Polymer 48, 5530-5540, (2007).

109.S. Mallakpour, Kowsari, E. J. Polym. Sci.,Part A: Polym. Chem. 43, 65456553, (2005).

110.S. Mallakpour, E. Kowsari, Iranian Polym. J. 15, 239-247, (2006).

111.S. Mallakpour, H. Yousefian, Polymer Bulletin 60, 191-198, (2008).

112.M. Messali, Arabian Journal of Chemistry 7(1), 63-70, (2014).

113.T. Maugard, M. Remaud-Simeon, D. Petre, P. Monsan, Tetrahedron 53,7587-7594, (1997).
92. C.J. Li, Chem. Rev. 105, 3095-3166, (2005).

93. W. Miao, T.H. Chan, Acc. Chem. Res. 39, 897-908, (2006).

94. D.A. Britz, A.N. Khlobystov, J.W. Wang, O’Neil, A.S. Poliakoff, M. A. Ardavan, G.A.D. Briggs, Chem. Commun. 176-177, (2004).

95. D.C. Rideout, R. Breslow, J. Am. Chem. Soc. 102, 7816-7817, (1980).

114.T. Maugard, M. Remaud-Simeon, D. Petre, P. Monsan, Tetrahedron 53, 7629-7634, (1997).

115.M. Gelo-Pujic, E. Guibe-Jampel, A. Loupy Tetrahedron 53, 17247-17254, (1997).

116.R. Rosu, M. Yasui, Y. Iwasaki, T. Yamane, J. Am. Oil Chem. Soc. 76, 839843, (1999).

117.K. Hill, O. Rhode, Fett-Lipid 101, 25-33, (1999).

118.P.T. Anastas, T.C. Warner, on Green Chemistry: Theory and Practice; Oxford University Press: London, 1998.

119.K. Sato, M. Aoki, J. Takagi, K. Zimmermann, R. Noyori, Bull. Chem. Soc. Jpn. 72, 2287-2306, (1999).

120.K. Sato, M. Aoki, R. Noyori, Science 281, 1646-1647, (1998).

121.X. Feng, J. Zhang, S. Cheng, C. Zhang, W. Li, B. Han, Green Chem. 10,578583, (2008).

122.M.A. Farajzadeh, M.R. Fallahi, Anal. Sci. 22, 635-63, (2006).

123.F. Genc, N.P. Milcheva, D.G. Hristov, K.B. Gavazov, Chem. Pap. 74, $1891-$ 1901, (2020)

124.P. Mukherjee, S.K. Padhan, S. Dash, S. Patel, P.K. Mohapatra, B.K. Mishra, J.Colloid Interface Sci. 355, 157-163, (2011).

125.P. Mukherjee, S. Sahu, S.K. Padhan, S. Dash, S. Patel, P.K. Mohapatra, B.K. Mishra, Ind. Eng. Chem. Res. 50, 11889-11896, (2011).

126.S.K. Padhan, P. Mukherjee, S. Dash, A. Tiwary, S. Patel, B.K. Mishra, Soft Materials. 14 (2), 157-163, (2016).

127.T. Liu, P. Cao, J. Geng, J. Li, M. Wang, M. Wang, X. Li, D. Yin, Food Chem. 142, 358-364, (2014).

128.O.G Makukha, L.A. Ivashchenko, O.A. Zaporozhets, Chem. Pap. 73, 693699, (2019). 